\title{
ПРИОРИТЕТНЫЕ НАПРАВЛЕНИЯ ИННОВАЦИОННОЙ МОДЕРНИЗАЦИИ КАК ОСНОВА УСТОЙЧИВОСТИ РОССИЙСКОЙ ЭКОНОМИКИ
}

\section{PRIORITY DIRECTIONS OF INNOVATIVE MODERNIZATION AS A BASIS FOR THE SUSTAINABILITY OF THE RUSSIAN ECONOMY}

N. Lebedev

S. Zubkova

Summary. The analysis of ways of predestination of innovative industrial modernization as a format of increasing the competitiveness of the domestic economy in the future is presented.

It is concluded that the economic stability of the domestic economy, achieved mainly due to the orientation of exports to the raw materials of the country, the export of goods of manufacturing industries can not be promising. It is necessary to overcome the fixation of exports to the country's raw materials without taking into account the export of goods from manufacturing industries, and to solve the problem of transition to the path of innovative modernization at an epoch-making level.

Keywords: innovative technologies, innovative modernization, industrial infrastructure, economic crises, competitiveness, financial support, innovations.

\author{
Лебедев Никита Андреевич \\ Д.э.н., nрофеессор, в.н.С., ФГБУН «Институт \\ экономики Российской академии наук» \\ ieras@inecon.org \\ Зубкова Светлана Валерьевна \\ К.э.н., дочент, Финансовый университет при \\ Правительстве Российской Федерации \\ Svzubkova@fa.ru
}

Аннотация. Представлен анализ путей предопределения инновационной производственной модернизации как формат наращивания на перспективу конкурентоспособности отечественной экономики.

Сделан вывод, что экономическая устойчивость отечественной экономики, достигаемая в основном за счёт ориентации экспорта на сырьевые ресурсы страны учёта экспорта товаров обрабатывающих отраслей не может быть перспективной. Необходимо преодолеть фиксацию экспорта на сырьевые ресурсы страны без учёта экспорта товаров обрабатывающих отраслей, на эпохальном уровне решить проблему перехода на путь инновационной модернизации.

Ключевые слова: инновационные технологии, инновационная модернизация, промышленная инфраструктура, экономические кризисы, конкурентоспособность, финансовое обеспечение, инновации.

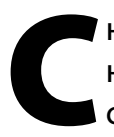

началом глобальных рыночных преобразований с 1992 г. модернизационные усилия в нашей стране не прекращались. В то же время, следует учесть, что модернизация не может не определяться действительным состоянием совокупной экономической конъюнктуры, оценка которой обнаруживает, что начало текущего века в развитии мировой экономики отмечено не устойчивостью, а, наоборот, периодами спадов и бурных финансовых кризисов [1]. Это, по преимуществу, финансовый кризис 2000-2001 гг. в Турции, который был вызван несбалансированностью госфинансов, аддукцией иностранных краткосрочных инвестиций для финансирования дефицита, привязанностью к внешним источникам финансирования [2]. Экономический кризис в Аргентине 2000-2004 гг., когда интересы частных иностранных инвесторов были проигнорированы в пользу правительства, что и стало причиной крупнейшего современного дефолта [3]. Представляет определённый интерес и характеристика экономического кризиса в Исландии, которая ока- залась незащищённой перед мировым кризисом в силу либерального подхода к госрегулированию и высоких показателей развития финансового сектора, когда формат банковских активов в десять раз превысил ВВП, а учётная ставка была наиболее высокой в мире, достигнув 15\%. Исландия фактически превратилась в оффшор, куда потянулись инвестиции. В подобных условиях к осени 2008 г. резко упал курс исландской кроны, кредиторская задолженность населения страны и иностранных инвесторов обвалили банковскую систему, которую национализировало правительство [4].

Ретроспективный обзор современных финансовых кризисов включает также рецессию начала века, которая затронула экономически развитые страны и характеризовалась общим экономическим спадом; предпосылки глобального кризиса 2007-2008 гг., который начался в Соединённых Штатах Америки, были связаны с невыплатами по ипотеке в сегменте нестандартного кредитования, что тогда вызвало падение стоимости 
ценных бумаг (закладных) и мировой экономический кризис [5].

К европейскому долговому кризису в 2010 г. привело обострение кризогенного фактора роста объёма задолженности в глобальном масштабе в государственном и частном секторе, а кроме того, антикризисные меры, предпринятые правительствами ряда европейских стран в наиболее уязвимых звеньях [6]. А 2014 год был уже отмечен финансовым кризисом в России. Его причины, лежащие на поверхности, выявлены рядом исследователей [7], однако, основная, скорее всего, выступает в фиксации экспорта на сырьевые ресурсы страны без учёта экспорта товаров обрабатывающих отраслей; снижение стоимости нефти на мировых рынках с июня 2014 г. почти на 40\% и спровоцировало двукратное падение курса рубля [8]. Эта ситуация усугубилась к тому же «украинскими» санкциями коллективного Запада, что со своей стороны подстегнуло инфляцию и предопределило системный кризис и гибридную войну в совокупности.

Но можно считать, что самым серьёзным мировым кризисом в этом веке стал всемирный коронакризис. Правительство РФ опубликовало список отраслей, наиболее пострадавших от последствий пандемии [9], которые легли на экономику. По оценке ИНП РАН в 2020 г. дегрессия отечественной экономики составит около $6 \%$ [10].

В этих условиях возникает приоритетная задача зафиксировать наиболее приемлемую траекторию будущего модернизационного развития, а ключевую денотацию приобретает инновационная модернизация как основа устойчивости российской экономики, показатели которой постоянно нарастают, что достаточно выразительно иллюстрируют инновационно развитые страны.

К тому же выбор приоритетного направления инновационной модернизации, как правило, знаменует прерогативы траектории, формулируемые целью производственной модернизации в соотношении с научно-техническим развитием и научными показателями.

Имеется мнение, что один из приемлемых путей предопределения инновационной производственной модернизации - это интеркаляция в промышленные отрасли сочетания инновационных технологий как формат наращивания на перспективу конкурентоспособности отечественной экономики [11]. Вместе с тем, согласно данным Счётной платы РФ, расходы на НИОКР в 2019 г. составили 422,0 млрд. руб., в 2020 г. планировалось выделить 519 млрд. руб., в 2021 г. эта сумма должна составить 486 млрд. руб.- соответственно 6-7 млрд. долл. [12]. В США на сайте Белого дома размещены данные относительно выделенных из бюджета сумм на научные исследования: в 2019 г.- 118 млрд. долл., в 2020 г.- 134 млрд. долл., в 2021 планируется ассигновать 142 млрд. долл., что соответствует 3\% ВВП (его величина в 2019 г. составила 21, 4 триллиона долл.). По данным СМИ Китая, частные и государственные инвестиции на науку в 2019 г. равнялись 322 млрд. долл., в 2020 г.- около 400,0 млрд. долл. По данным статистической службы ЕС, страны Евросоюза в 2019 г. направили на НИОКР 396 млрд. евро бюджетных инвестиций.

Проблема заключается в том, что в России на эпохальном уровне не решен переход на путь инновационной модернизации; решение заключено в необходимости инвестирования в фундаментальные научно-технические исследования как минимум трёх процентов ВВП. Тем не менее, анализ Института статистических исследований и экономики знаний НИУ ВШЭ показывает, что отечественные расходы на гражданские научно-технические и научно-исследовательские разработки в экономике составили в 2019 г. 1,03\% ВВП (1,13 трлн. руб.), причём, в постоянных ценах показатель снизился (в 2010 г.-1,13\% ВВП).

Ключевым ресурсом инвестирования гражданских научно-технических и научно-исследовательских разработок по-прежнему остаётся бюджет (в 2019 г. 66,3\%; 70,3\% - в 2010 г.). Хотя статистика затрат несколько колеблется: так, если НИУ ВШЭ приводит цифру бюджетных затрат на гражданскую науку в 2019 году в сумме 489 млрд. руб. (0,44\% ВВП в 2019 г. и 0,53\% в 2010 г.), то по данным Счётной платы РФ, как отмечалось выше, расходы на НИОКР в 2019 г. составили 422,0 млрд. руб.

Что касается выделения средств в 2021 г., то в пояснительной записке на проект федерального бюджета 2021-2023 гг. отмечается, что бюджетные расходы, касающиеся гражданских научно-технических и научно-исследовательских исследований и разработок будут сокращены на 6,3\% (до 486,1 млрд. руб.); относительно прошлогоднего закона о бюджете экономия в 2021 г. составит 1,6\% и в 2022 г.- 2,5\% [13].

Как мы видим, статистика подтверждает, что внедренческая среда как база, связывающая науку с производством в России складывается весьма слабо, а состояние научно-инновационной сферы показывает её деградацию. В чём же первоначальные предпосылки деградации, почему инновационная политика не упрочивает ситуацию, не служит преодолению сырьевой направленности, не превращает страну в одного из лидеров научных исследований и разработок? 
Таблица 1. Отдельные показатели инновационной деятельности

\begin{tabular}{|c|c|c|c|c|}
\hline & 2016 & 2017 & 2018 & 2019 \\
\hline $\begin{array}{l}\text { Отгружено товаров собственного производства, } \\
\text { выполнено работ и услуг собственными силами } \\
\text { (млн. руб.) }\end{array}$ & 51316283,5 & 57611057,8 & 68982 626,6 & 92253929,6 \\
\hline $\begin{array}{l}\text { В т.ч. инновационные товары, работы, услуги } \\
\text { (млн. руб.) }\end{array}$ & 4364321,7 & 4166998,7 & 4516276,4 & 4863381,9 \\
\hline $\begin{array}{l}\text { Удельный вес инновационных товаров, работ, } \\
\text { услуг в общем объёме отгруженных товаров, } \\
\text { выполненных работ, услуг (\%) }\end{array}$ & 8,5 & 7,2 & 6,5 & 5,3 \\
\hline $\begin{array}{l}\text { Затраты на инновационную деятельность (млн. } \\
\text { руб.) }\end{array}$ & 1284590,3 & 1494985,3 & 1472822,3 & 1954133,3 \\
\hline $\begin{array}{l}\text { Удельный вес затрат на технологические } \\
\text { инновации в общем объёме отгруженных } \\
\text { товаров, выполненных работ, услуг (\%) }\end{array}$ & 2,5 & 2,4 & 2,1 & 2,1 \\
\hline
\end{tabular}

Источник: rosinfostat.ru/inovatsii/\#i-4

Как один из негативных факторов следует выделить состояние действующего законодательства. Так, обзор изменений Налогового кодекса РФ показывает, что в 2016 году НК РФ был изменён и дополнен пять раз, в 2017 году - четыре раза, в 2018 году - пять раз, в 2019 году - трижды, в 2020 году - 9 и 23 декабря. В 2021 году изменения вносились в феврале и трижды - в апреле [14]. В Таможенный кодекс Евразийского экономического союза добавлено одиннадцать новых статей; последняя его редакция действует с 23 марта 2021 г. [15].

Анализ показывает, что общая продуктивная организационная концепция инновационной деятельности ещё не сформирована; вместе с тем, комиссия Госсовета по инвестициям уже разрабатывает единые правила инвестирования на уровне регионов как прообраз информационного портала содействия инвестиционным проектам. Первый блок правил будет включать инвестиционную декларацию, в которую будут включены планы инвестиционного развития того или иного региона, ориентиры и промоушн инвесторов. Второй блок вберёт в себя свод инвестиционных правил с пошаговыми алгоритмами ключевых действий (например, получение различной разрешительной документации). На первом этапе новые правила будут внедряться в пяти областях страны [16]. Это в определённой степени, возможно, переориентирует экономику из состояния усиливающего хаоса на изменчивость динамики спроса, сформирует набор требований, необходимый для инновационного развития, репродуцирует праксис промышленных отраслей регулировать интегративные задачи. Но надо понимать, что для форсирования инновационной депрессии потребуется прирост инновационной продукции к 2030 г. до 35\% (5,3\% - в 2019 г.), что улучшит экономическую ситуацию и повысит конкурентоспособность.

Важно отметить, что кроме преодоления инновационной депрессии для усиления инновационной модернизации не менее важно, как сказано в «Основных направлениях бюджетной, налоговой и таможенно-тарифной политики на 2020 год и на плановый период 2021 и 2022 годов», «расшить имеющиеся узкие места, ограничивающие полноценное экономическое развитие». С этой точки зрения будут вводиться стимулирующие налоговые и финансовые меры, в частности, субъекты Федерации будут наделены правом определять объём инвестиционного налогового вычета по расходам на научно-исследовательские работы; предусмотрена разработка законопроекта, защищающего и поощряющего капиталовложения и развитие инвестиционной деятельности, которым инвесторам будет предоставлена «базовая» налоговая стабилизация по основным видам налогов с возможностью компенсировать затраты на создание инфраструктуры за счёт вновь уплачиваемых налогов и пр.[17], что, по мнению идеологов «Основных направлений...», будет стимулировать инвестиционную деятельность.

Сегодня же налоговая политика архаична, не способствует промышленному развитию, не стимулирует инновационный рост, хотя, мультипликативный эффект от снижения налоговых ставок, как считается, мог бы вполне покрыть снижение бюджетных доходов от сокращения налоговой нагрузки - совокупная ставка налогов из прибыли российского среднего предприятия составляет $30 \%$ (22\% - в Пенсионный фонд; 10\%в Фонд страхования; 5,1\% - в медстрах; до 2,9\% - со- 
цстрах), тогда как в США, ЕС и ряде бывших советских республик совокупная ставка налогов на труд из прибыли предприятия не превышает 10\%.

Первостепенные направления инновационной модернизации для придания устойчивости российской экономике разработаны Комиссией по модернизации и технологическому развитию экономики страны при президенте страны, когда ещё на её первом заседании была отмечена необходимость «начать модернизацию без промедления», определены отрасли, обладающие масштабным мультипликативным эффектом, потенциалом, чтобы вытянуть смежные направления и общезначимые проекты [18].

Среди обозначенных первостепенных направлений, в частности, встаёт такая масштабная отрасль как гражданское авиастроение. Хотя в Прогнозе научно-технологического развития Российской Федерации на период до 2030 года [19] не были сформулированы стимулы, способствующие инновационной модернизации гражданского авиастроения, в правительственном Постановлении № 312 от 20 марта 2020 г. утверждены изменения в госпрограмму «Развитие авиационной промышленности», цель которых добиться создания конкурентоспособной авиационной отечественной промышленности [20], что, как нам представляется, возможно реализовать в фокусе модернизации.

Согласно обновлённой госпрограмме, для устойчивой положительной динамики в развитии отрасли планируется выделить дополнительно 170 млрд. руб. до 2025 года, и, т.о., общий объём финансирования составит 912 млрд. руб. на прорывные, но зависшие разработки самолёта MC-21 с крылом, выполненным по технологии вакуумной инфузии из композитных материалов и инновационным фюзеляжем. Кроме того, в этот бюджет включены разработки совместного российско-китайского самолёта CR -929 и турбовинтового самолёта Ил-114. Обновлённая программа даст возможность, как можно надеяться, освоить требуемый объём выпуска модернизированных авиалайнеров. Часть выделяемых средств (48,1 млрд. руб.) пойдут на развитие подпрограммы «Авиационное двигателестроение», и, в частности, на разработку двигателя ПД-35 и ТВ7-117 для этих самолётов, в конструкции которых будут широко использованы нанотехнологии - новые композитные высокомодульные материалы с улучшенными функциональными свойствами, например, высокопрочная сталь, эпоксидные композиты, разного рода сплавы, полимеры, порошковые сплавы, что дат возможность создать изделия с уникальными свойствами [21]. Как мы видим, поставлена задача наращивать и модернизировать парк отечественных гражданских самолётов, заменить устаревший импортный авиапарк.
Предусмотренными мерами должны быть, во-первых, решена задача восстановления коммуникаций, a, во-вторых, решена задача обеспечения эффекта «коммуникативного сжатия пространства» - сокращения времени в пути [22].

Вместе с тем, смета финансирования будет утверждена следующим бюджетом и вполне возможна ситуация перераспределения расходов, когда авиастроение в очередной раз может оказаться заложником сокращения расходов, поэтому будет ли решена задача по формированию модернизированной технологической базы и будет ли преодолён спазм отечественного авиастроения, всё же покажет время [23].

В связи с анализом проблемы, важно отметить и сопряженные задачи, в частности, важность развития материальной базы по отношению к практике модернизации. Так, нефтегазовому комплексу проектом Энергетической стратегии до 2035 года как ключевые цели определены модернизация, повышение конкурентоспособности, развитие инфраструктуры, цифровая трансформация. Отдельной задачей определены необходимость роста уровня технической оснащённости ряда предприятий нефтепереработки, внедрения инновационных технологий, эффективного решения энергетического ресурсосбережения. Для чего, в рамках модернизации, важно осваивать инновации в сфере разведки месторождений, осваивать ударные технологии, чтобы как минимум поддержать достигнутый уровень добычи углеводородов.

Мы полагаем, что сказанное обнажает специфику обеспечения инновационного пути развития российской экономики как основу её устойчивости, что при комплексном подходе и при совокупности с другими мероприятиями позволит добиться от их осуществления максимального эффекта.

Понятно, что устойчивость российской экономики не может быть перспективной за счёт эксплуатации только лишь природного потенциала. Для этого важно создать условия, чтобы такие сферы вложения капитала, как например, сельское хозяйство, являющееся сырьевой основой для производства продуктов питания, стала привлекательной. Не менее привлекательной может стать сфера легкой промышленности, где активность отечественного бизнеса, его инновационные и инвестиционные возможности всё ещё слабо выражены. Устойчивость российской экономики не может быть повышена без учёта роста развития малого и среднего предпринимательства, стимулирования конкуренции.

Анализ показывает, что необходимо преодолеть фиксацию экспорта на сырьевые ресурсы страны без 
учёта экспорта товаров обрабатывающих отраслей, на эпохальном уровне решить проблему перехода на путь инновационной модернизации - её решение заключено в том числе, в необходимости инвестирования достаточных средств в фундаментальные научно-технические исследования.
С этой точки зрения наиболее существенное значение придаётся усилиям органов государственной власти, которые должны видеть в обеспечении инновационной модернизации как основы устойчивости отечественной экономики приоритетное направление своей деятельности.

\section{ЛИТЕРАТУРА}

1. Воробьёва И.П. Устойчивость экономики и проблемы её обеспечения в современной России. [Текст]. И.П. Воробьёв // Вестник Томского государственного университета.— 2012. — № 1 (17). С. - 17-25.

2. Сидорова Ю.Б. Валютно-финансовый кризис в Турции 2000-2001 гг. // Востоковедный сборник.— Вып.5-й._- М., 2003.—C. 328.

3. Щипкова Е.А. США, международный валютный фонд и экономический кризис в Аргентине (2001-2004 гг.) // Вестник Томского государственного университета. - 2013. - № 375. С- 109-111.

4. Кузнецова Н.П. Исландия — первая жертва глобального кризиса // Вестник СПбУ.—Cер. 5. — 2009. — Вып.2.—C. 20-21.

5. Попов В.Н., Орешков А.А. Американский ипотечный кризис: предпосылки, причины, опыт для России // Финансы и кредит.- № 30 (366).—2009.C. $17-18$

6. Серёгина С., Ларионова М. Европейский долговой кризис и новые направления реформирования механизмов экономической политики ЕС // Российский экономический журнал. - № 6. - 2012.- С. 68-69.

7. Винокуров М.А. Экономический кризис в России 2014 года и возможные пути его преодоления // Известия Иркутской государственной экономической академии. - 2015.-Т. 25.- № 2.-С. 261-267.

8. Вхождение России в кризис (конец 2014 — начало 2015 года) // Бюллетень социально-экономического кризиса в России. — Выпуск № 1, апрель 2015. Аналитический центр при Правительстве Российской Федерации.

9. Постановление Правительства РФ от 3 апреля 2020 г. № 434 «06 утверждении перечня отраслей российской экономики, в наибольшей степени пострадавших в условиях ухудшения ситуации в результате распространения ново коронавирусной инфекции» (с изм. и доп. 0 т 16 октября 2020 г.) // www.garant.ru

10. Мунтиян В.И. Экономический рост: проблемы и пути решения // Экономический рост в Российской Федерации: перспективы и пути обеспечения / Сборник аналитических материалов фракции Политической партии «Справедливая Россия» в Государственной Думе ФС РФ.- М.: Издание Государственной Думы, 2020.-С. 30.

11. Кулиш С.М. Роль инновационных технологий в развитии российской промышленности // Вестник экономики, права и социологии. — 2016. — № 2.— C. 60-62.

12. ach.gov.ru/checks $/ 9658$

13. minfin.gov.ru/performance/budget/federal_budget/budget/2020/

14. www.consultant.ru/document/cons_doc_LAW_327521/

15. www.consultant.ru/document/cons_doc_LAW_215315/

16. Белов С. В России разрабатывают единые правила инвестирования на уровне регионов // Российская Газета RG.RU/ 01/04.2021

17. Основные направления бюджетной, налоговой и таможенно-тарифной политики на 2020 год и на плановый период 2021 и 2022 годов. 一 М.: Министерство финансов Российской Федерации, 2019.- - С. 30,32.

18. Указ Президента РФ от 20 мая 2009 г. № 579 «0 Комиссии при Президенте Российской Федерации по модернизации и технологическому развитию экономики России»; Положение о Комиссии при Президенте Российской Федерации по модернизации и технологическому развитию экономики России (в ред. Указа Президента РФ от 30.04.2010 № 532); Указ Президента РФ от 18.06.2012 № 878 «0 Совете при Президенте РФ по модернизации экономики и инновационному развитию России» (с изм. от 22 ноября 2016 г.).

19. Прогноз научно-технологического развития России Федерации на период до 2030 года (утв. Правительством РФ 3 января 2014 г.) // www.garant.ru

20. 0 внесении изменений в государственную программу Российской Федерации «Развитие авиационной промышленности» / Постановление Правительства Российской Федерации от 20 марта 2020 г. № 312 //www.garant. ru

21. Моляр, А.Г. и др. Конструкционные материалы в самолётостроении. / [Текст]. А.Г. Моляр // К.: КВИЦ, 2015.

22. Прогноз научно-технологического развития России Федерации на период до 2030 года (утв. Правительством РФ 3 января 2014 г.) // www protown.ru

23. Газета «Коммерсантъ».— № 55 от 27.03.2020.—C. 8 